\title{
Family-centeredness of childhood obesity interventions: psychometrics \& outcomes of the family-centered care assessment tool
}

\author{
Meg Simione ${ }^{1,2^{*}}$ (D), Mona Sharifi ${ }^{3}$, Monica W. Gerber ${ }^{1}$, Richard Marshall ${ }^{4}$, Earlene Avalon ${ }^{5}$, Lauren Fiechtner ${ }^{1,2,6}$,
} Christine Horan ${ }^{1}$, E. John Orav ${ }^{7}$, Joseph Skelton ${ }^{8}$ and Elsie M. Taveras ${ }^{1,2,9}$

\begin{abstract}
Background: Incorporating family-centered care principles into childhood obesity interventions is integral for improved clinical decision making, better follow-through, and more effective communication that leads to better outcomes and greater satisfaction with services. The purpose of this study is to evaluate the psychometric properties of a modified version of the Family Centered-Care Assessment (mFCCA) tool and to assess the familycenteredness of two clinical-community childhood obesity interventions.
\end{abstract}

Methods: Connect for Health was a randomized trial testing the comparative effectiveness of two interventions that enrolled 721 children, ages $2-12$ years, with a body mass index (BMI) $\geq 85$ th percentile. The two arms were (1) enhanced primary care; and (2) enhanced primary care plus contextually-tailored, health coaching. At the end of the one-year intervention, the mFCCA was administered. We used Rasch analyses to assess the tool's psychometrics and examined differences between the groups using multiple linear regression.

Results: 629 parents completed the mFCCA resulting in an $87 \%$ response rate. The mean (SD) age of children was 8.0 (3.0) years. The exploratory factor analysis with 24 items all loaded onto a single factor. The Rasch modeling demonstrated good reliability as evidenced by the person separation reliability coefficient (0.99), and strong validity as evidenced by the range of item difficulty and overall model fit. The mean (SD, range) mFCCA score was 4.14 $(0.85,1-5)$. Compared to parents of children in the enhanced primary care arm, those whose children were in the enhanced primary care plus health coaching arm had higher mFCCA scores indicating greater perception of familycenteredness ( $\beta=0.61$ units [95\% Cl: 0.49, 0.73]).

Conclusions: Using the mFCCA which demonstrated good psychometric properties for the assessment of familycentered care among parents of children with obesity, we found that individualized health coaching is a familycentered approach to pediatric weight management.

Trial registration: Clinicaltrials.gov NCT02124460.

Keywords: Childhood obesity, Pediatric weight management, Family-centered outcomes, Primary care

\footnotetext{
* Correspondence: msimione@mgh.harvard.edu

'Division of General Academic Pediatrics, Department of Pediatrics,

MassGeneral Hospital for Children, 125 Nashua Street, Suite 860, Boston, MA

02114, USA

2Department of Pediatrics, Harvard Medical School, Boston, MA, USA

Full list of author information is available at the end of the article
}

(c) The Author(s). 2020 Open Access This article is licensed under a Creative Commons Attribution 4.0 International License, which permits use, sharing, adaptation, distribution and reproduction in any medium or format, as long as you give appropriate credit to the original author(s) and the source, provide a link to the Creative Commons licence, and indicate if changes were made. The images or other third party material in this article are included in the article's Creative Commons licence, unless indicated otherwise in a credit line to the material. If material is not included in the article's Creative Commons licence and your intended use is not permitted by statutory regulation or exceeds the permitted use, you will need to obtain permission directly from the copyright holder. To view a copy of this licence, visit http://creativecommons.org/licenses/by/4.0/ The Creative Commons Public Domain Dedication waiver (http://creativecommons.org/publicdomain/zero/1.0/) applies to the data made available in this article, unless otherwise stated in a credit line to the data. 


\section{Background}

Family-centered care is a set of principles that aim to promote a partnership between families and health care practitioners through respect, trust, open and objective communication, and joint decision making [1-3]. The principles rely on underlying assumptions that parents know their children best, all families are unique, and supportive family and community contexts result in the best outcomes [4]. By incorporating family-centered care principles into pediatric care, it results in improved clinical decision making, increased follow-through, and more effective communication that leads to better child health outcomes and greater satisfaction with services [5, 6]. Given the high attrition rates of pediatric weight management programs, creating programs that focus on family-centered care by engaging families and addressing family's concerns and priorities may improve satisfaction that may ultimately lead to less attrition in weight management programs $[6,7]$.

Having reliable and valid tools to measure the familycenteredness of clinical programs and research trials is important, as it will help to ensure these principles are incorporated into care. Examples of scales to assess family-centered care include the Medical Home Family Index [2] and the Consumer Assessment of Healthcare Providers and Systems Clinician and Group Survey [8]. Both instruments are widely used, but neither scale encompasses all the core principles represented in familycentered care. For example, they lack questions about honoring cultural diversity and traditions, and shared decision-making. The Family Centered Care Assessment (FCCA) is a tool for parents that was developed to evaluate the family-centeredness of healthcare services for children with special healthcare needs [9]. It was developed by experts from Family Voices, a family advocacy organization, the American Academy of Pediatrics, and the Maternal and Child Health Bureau. It was administered to 790 parents and was found to be reliable and valid [9]. A strength of the FCCA is the representation of eight family-centered care principles across the 24 questions which include communication with providers, decision-making interactions, future orientation and planning, strength-based care approach, care coordination, cultural and linguistic competent care, practice structure and policies that support family-centered care, and family support.

In the Connect for Health trial, a clinical-community childhood obesity intervention trial [10, 11], a modified version of the FCCA (mFCCA) that had more relevant items for parents of children with obesity than the original version was administered to parents. Our aims were to assess the psychometric properties of the mFCCA and to evaluate the family-centeredness of the Connect for Health trial for childhood obesity.

\section{Methods}

We used data from the Connect for Health trial to assess the psychometric properties of the mFCCA and to evaluate differences in family-centeredness between the two intervention arms. Connect for Health was a blinded, randomized control trial testing the comparative effectiveness of two clinical-community childhood obesity interventions by examining child body mass index (BMI) z-scores and family-centered outcomes for childhood obesity $[10,11]$. The trial was one-year and conducted in six pediatric practices in Massachusetts. A total of 721 children, ages $2-12$ years, with a BMI $\geq 85$ th percentile for age and gender were enrolled in the trial. We randomized children into one of two intervention arms: [1] enhanced primary care $(n=361)$; or [2] enhanced primary care plus contextually tailored, health coaching $(n=360)$. The enhanced primary care arm included electronic health record enhancements such as best practice alerts, clinical decision support tools, educational materials; and families received neighborhood resource guides and monthly text messaging. The health coaching arm received the electronic health record enhancements in addition to contextually-tailored health coaching support via six telephone/ video contacts, an online, interactive community resource map, and twice-weekly text messaging. Both arms were designed to be family-centered, for example, through educational materials and connecting families to resources. The study design, setting, details of the intervention, and results of the primary outcomes of the trial have previously been described in more detail $[10,11]$. The Partners Institutional Review Board approved the trial and it was registered in clinicaltrials.gov.

\section{Development of the mFCCA}

At the end of the one-year intervention, we administered the mFCCA to parents. The mFCCA was developed with the input of the authors of the FCCA [9]. Five questions from the original scale were replaced with questions that were more applicable to children with obesity. The original authors provided alternate questions from their previously developed question bank that preserved the psychometrics of the scale. We included questions about addressing parental concerns, helping to find resources, identifying support systems, promoting mental health, and planning for changes in weight management or behavior change routines. These questions replaced items regarding disagreeing with healthcare professionals about recommendations, modifying daily care and treatment routines, ways to pay for things that insurance does not cover, understanding content in the medical record, and discussing hopes for the child's future. Study investigators reviewed the final questions to ensure content validity for childhood obesity. The modified scale had 24 items that represented principles of family- 
centered care that resulted in eight different topical areas similar to the original scale. Responses to the scale were ordinal ranging from 1 to 5 with higher scores representing a greater perception of family-centeredness. A "not applicable" response was also provided.

\section{Psychometric analyses of the MFCCA}

Our first objective was to assess the psychometric properties of the mFCCA using Rasch modeling [12-15]. The original scale was developed using item response theory, and those analyses were replicated in this study. Only children in the enhanced primary care arm were included in the psychometric analyses as this arm answered questions in relation to services from primary care providers (rather than health coaches) which is more representative of usual care. Because we made modifications to items, we performed an exploratory factor analysis using the principal axis method for factor extraction to confirm the uni-dimensionality of the scale rather than performing a confirmatory factor analysis. Prior to analysis, we determined that any item with a low factor loading $<0.4$ would be deleted as was done in the original analyses [9]. We also examined the Scree plot and reviewed the tests of the hypothesis results. We calculated item total correlations to examine the homogeneity of the scale and determined any correlations < 0.3 would be deleted. We then used Rasch analysis using a partial credit model to assess the overall fit of the items [16-18]. We calculated Chi-square based itemfit statistics that explain how well the data fit the model, including infit and outfit statistics that detected inliers and outliers, respectively. We set our criteria for item inclusion to be within the range of $0.5-1.5[19,20]$. For each item, we also calculated standard error of the item score and item difficulty. Item difficulty was expressed using a logit scale (centered at 0 ) that ranges from negative (represents easy items) to positive (represents more difficult items) and measures how challenging it is to implement each item into clinical practice [13]. "Easy" items represent principles of family-centered care that would be easy to incorporate into care (i.e., taking time to address family's concerns), whereas "difficult" items would be more challenging to incorporate into clinical practice. To test for potential question bias, we performed Differential Item Functioning (DIF) [21, 22], a statistical test that examines whether an item is measuring different abilities for subgroups, and tested for sex, income, race, and ethnicity. For the above analyses, "not applicable" responses were set to missing because they were considered structurally missing and mean imputation was used for other missing responses [23]. We deleted items that did not fall within acceptable predetermined ranges of the described analyses and the Rasch analysis was iterated until all items demonstrated a good fit. Once a final set of items was determined, we calculated person separation reliability to assess the internal consistency of the scale. This metric is equivalent to a Cronbach's alpha [24, 25].

\section{Family-Centered Outcomes \& Statistical Analyses}

Our second aim was to determine the familycenteredness of the two intervention arms. First, we described overall participant characteristics according to intervention arm. For each participant, we derived a score by calculating the mean of the final items (items that were determined to show good model fit). Due to missing data, we calculated mean scores rather than a total score as was done in the original paper. We treated "not applicable" and missing responses in a similar manner as we did for the psychometric analyses described above. We used multiple linear regression adjusting for study site to examine the outcomes between the two intervention arms and determine the regression coefficient and 95\% confidence intervals. We set our alpha level at 0.05 to test for statistical significance. All analyses were performed using $\mathrm{R}$ version 3.4.4 and the eRM and lordif packages $[16,22,26]$.

\section{Results}

After the one-year intervention, 629 parents completed the mFCCA resulting in an $87 \%$ response rate. Participants who had "not applicable" or missing responses for $>50 \%$ of items were excluded from the analyses. A total of 316 children in the enhanced primary care arm and 313 children in the enhanced primary care plus health coaching arm were included in the final analyses. Overall, the mean (SD) age of children enrolled in the study was 8.0 (3.0) years, and $35.5 \%$ of children were nonHispanic White, $34.2 \%$ were non-Hispanic Black, 21\% were Hispanic, and $9.4 \%$ were other races. Table 1 shows characteristics of the children and their parents.

\section{Psychometric analyses}

For the psychometric analysis, 316 responses (enhanced primary care arm only) were included. The results of the exploratory factor analysis revealed the presence of a single factor (eigen value $=11.24$ ) which explained $47 \%$ of the variance (see Fig. 1). Individual item factor loadings were all $>0.4$ and the item total correlations for the individual items were all $>0.3$. Based on the factor loadings and item total correlations, no items were deleted at this stage of the analyses. Rasch item fit statistics revealed that 22 items fell between the range of $0.5-1.5$. The two items (items \#8 and \#13) that were outside of the range were not deleted from the final scale because of their strong factor loadings $(0.82$ and 0.83 , respectively) and strong item total correlations (0.75 and 0.76, respectively). The questions showed a broad range of 
Table 1 Child, Parent, and Household Characteristics According to Connect for Health Intervention Arm

\begin{tabular}{|c|c|c|c|c|}
\hline & \multicolumn{4}{|l|}{ No. (\%) } \\
\hline & Overall & Enhanced Primary Care & Enhanced Primary Care plus Health Coach & $\boldsymbol{P}$ Value \\
\hline & $N=629$ & $N=316$ & $N=313$ & \\
\hline \multicolumn{5}{|l|}{ Child Characteristics } \\
\hline Age, mean (SD) & $8.04(2.98)$ & $7.96(3.0)$ & $8.12(2.96)$ & 0.52 \\
\hline Sex & & & & 0.55 \\
\hline Male & $301(47.90 \%)$ & $147(46.5 \%)$ & $154(49.2 \%)$ & \\
\hline Female & $328(52.1 \%)$ & $169(53.5 \%)$ & $159(50.8 \%)$ & \\
\hline Race/ ethnicity & & & & 0.32 \\
\hline Non-Hispanic white & $223(35.5 \%)$ & $119(37.7 \%)$ & $104(33.2 \%)$ & \\
\hline Non-Hispanic black & 215 (34.2\%) & $99(31.3 \%)$ & $116(37.1 \%)$ & \\
\hline Hispanic/Latino & $132(21.0 \%)$ & $71(22.5 \%)$ & $61(19.5 \%)$ & \\
\hline Other & $59(9.38 \%)$ & $27(8.54 \%)$ & $32(10.2 \%)$ & \\
\hline BMI, mean (SD) & $23(4.81)$ & $23(4.62)$ & $23(5.01)$ & 0.82 \\
\hline BMI z-score, mean (SD) & $1.89(0.52)$ & $1.91(0.51)$ & $1.87(0.53)$ & 0.28 \\
\hline \multicolumn{5}{|l|}{ Parent Characteristics } \\
\hline Age, mean (SD) & $38.6(7.31)$ & $38.8(7.57)$ & $38.3(7.04)$ & 0.37 \\
\hline \multicolumn{5}{|l|}{ BMl } \\
\hline$<25$ & $140(22.8 \%)$ & $70(22.9 \%)$ & $70(22.7 \%)$ & 0.99 \\
\hline $25-29$ & $210(34.1 \%)$ & $105(33.2 \%)$ & $105(34.0 \%)$ & \\
\hline$\geq 30$ & $265(43.1 \%)$ & $131(41.5 \%)$ & $134(43.4 \%)$ & \\
\hline Income & & & & 0.03 \\
\hline$\leq \$ 50,000$ & $261(42.3 \%)$ & $118(37.9 \%)$ & $143(46.7 \%)$ & \\
\hline$>\$ 50,000$ & $356(57.7 \%)$ & $193(62.1 \%)$ & $163(53.3 \%)$ & \\
\hline Education, $<$ college graduate & $302(48.2 \%)$ & $163(51.6 \%)$ & $139(44.7 \%)$ & 0.10 \\
\hline
\end{tabular}

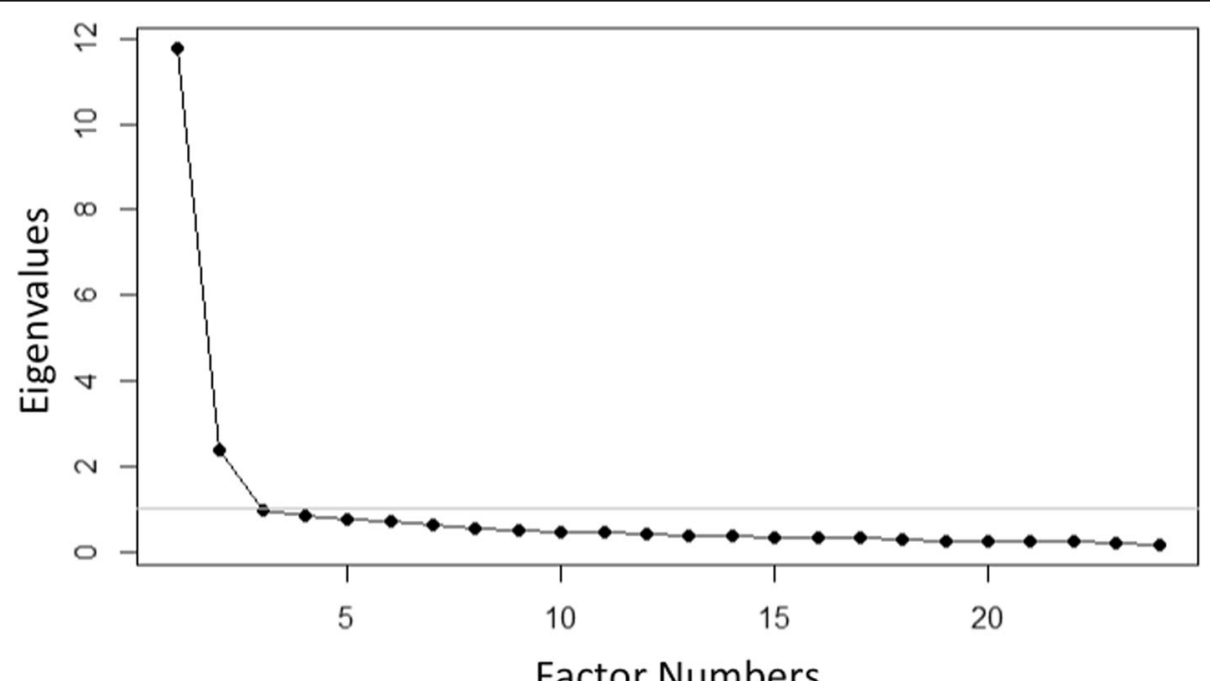

Factor Numbers

Fig. 1 Exploratory factor analysis Scree plot of the modified Family-Centered Care Assessment Tool 
item difficulty ranging from -1.22 logits (easiest) to 1.10 logits (most difficult). The DIF analyses did not reveal question bias for sex, income, race, and ethnicity as the pseudo $R^{2}$ measures were $<0.02$. In a no DIF condition, we would expect that pseudo $R^{2}$ measures to be $<0.02$ [22]. Results of the psychometric analyses are shown in Table 2. Based on the psychometric analyses, we did not remove any items and the final 24 items represented eight core principles of the family-centered care. After finalizing the items of the mFCCA, we calculated the person separation reliability which was 0.99 revealing high internal consistency of the scale.

\section{Family-centered outcomes}

The mean score (SD) for the final 24 items of the mFCCA was 3.84 (0.95) for the enhanced primary care arm and $4.45(0.61)$ for the enhanced primary care plus health coaching arm (Table 3). Figure 2 shows the mean responses for the final items on the mFCCA for both intervention arms. Compared to parents of children in the enhanced primary care arm, those whose children were in the enhanced primary care plus health coaching arm had higher mFCCA scores indicating greater perception of family-centeredness $(\beta=0.61$ units [95\% CI: $0.49,0.73])$.

\section{Discussion}

The purpose of this study was to evaluate the psychometric properties of the mFCCA and to assess the family-centeredness of the Connect for Health trial for childhood obesity. We found the mFCCA to be a reliable and valid instrument for assessing family-centeredness. We also found that the intervention arm that received enhanced primary care plus health coaching had a higher score on mFCCA indicating a greater perception of family-centeredness than the intervention arm that received enhanced primary care only.

Using exploratory factor analysis, we determined that the 24 items in the mFCCA all loaded onto a single factor; and using Rasch analysis we determined the scale had good reliability as evidenced by the high person separation reliability coefficient, and strong validity as evidenced by the range of item difficulty, the absence of DIF items, and the overall model fit. Our findings were similar to the original version of the FCCA [9] despite exchanging five questions from the original version and testing the scale on a different population (children with overweight or obesity v. children with special healthcare needs). The mFCCA had a range of item difficulties, which is important in item response theory to distinguish performance between high and low performers. For example, if a scale only had "easy" questions then we would be unable to discern programs that had a high degree of family-centeredness from a low degree.
Interestingly, several of the items that were found to be the most difficult and less likely to be incorporated into care, were items representing cultural and linguistic competence in care which is a principle not represented in other family-centered scales [2, 8, 9]. Given the widening gap of racial/ ethnic disparities in childhood obesity rates [27], these principles represent important components of family-centered care that ensures all families are engaged in services.

After assessing the reliability and validity of the scale, we then evaluated the family-centeredness of the interventions. The intervention arm that received enhanced primary care plus health coaching was found to have a greater perception of family-centered care than the arm that received enhanced primary care only. The health coaching arm had a mean score of 4.5 indicating that most responses fell between "usually" or "almost always", whereas the enhanced primary care arm had a mean score of 3.8 indicating that most responses fell between "sometimes" or "usually". The parents in the enhanced primary care plus health coaching arm tended to score items that were more difficult (based on item difficulty scores) higher than the other arm did suggesting that the services they received incorporated in more familycentered care principles. Other notable item-level differences between the two arms included using language that a family understands, considering the family's schedule when making appointments, and asking about what is working. Over $90 \%$ of respondents in the enhanced primary care plus health coaching arm answered "almost always" as compared to less than $70 \%$ in the enhanced primary care arm. The enhanced primary care plus health coaching arm may have perceived their care as more family-centered due to numerous aspects of the design of the intervention, including regular contact with a health coach through phonecalls or video chats, interactive text messaging with behavioral goals [28], and the tailored family resources provided to them. As previously reported, this arm was also found to have better adherence to the different components of the intervention including the text messaging program and use of the neighborhood resource guide [11]. Although the enhanced primary care plus health coaching arm received a higher dosage of the intervention, based on the individual item level differences between the two arms, it appears that the differences in family-centeredness may be attributable to other factors besides amount of care and attention. For example, the enhanced primary care plus health coaching arm were more likely to respond "almost always" to questions relating to using understandable words, asking what is going well, connecting family to resources, and discussing the child's overall health and well-being. 
Table 2 Estimates of Item Difficulty, Standard Error, Mean-Square Fit Statistics, Item-Total Correlations, and Topical Area of the Modified Family Centered Care Assessment Tool

\begin{tabular}{|c|c|c|c|c|c|c|c|}
\hline Item \# & $\begin{array}{l}\text { My child's health care } \\
\text { provider/ health coach ... }\end{array}$ & Item Difficulty & $\begin{array}{l}\text { Standard Error } \\
\text { of Item Score }\end{array}$ & $\begin{array}{l}\text { Infit Mean- } \\
\text { Square Value }\end{array}$ & $\begin{array}{l}\text { Outfit Mean- } \\
\text { Square Value }\end{array}$ & $\begin{array}{l}\text { Item Total } \\
\text { Correlation }\end{array}$ & Topical Area \\
\hline $4^{a}$ & $\begin{array}{l}\text { Takes enough time to address } \\
\text { my concerns }\end{array}$ & -1.22 & 0.03 & 0.84 & 0.96 & 0.59 & Communication \\
\hline 7 & $\begin{array}{l}\text { Talks with me about my child's } \\
\text { overall health and well-being }\end{array}$ & -1.09 & 0.03 & 0.82 & 0.58 & 0.63 & Future Promotion \\
\hline 1 & $\begin{array}{l}\text { Talks with me using words I } \\
\text { understand }\end{array}$ & -0.93 & 0.03 & 1.26 & 1.16 & 0.51 & Communication \\
\hline 2 & $\begin{array}{l}\text { Supports me in the role that I } \\
\text { want to take }\end{array}$ & -0.89 & 0.03 & 0.95 & 0.74 & 0.59 & Decision Making \\
\hline 12 & $\begin{array}{l}\text { Recognizes my strengths in } \\
\text { caring for my child }\end{array}$ & -0.76 & 0.04 & 0.99 & 0.90 & 0.61 & Strength-Based \\
\hline 10 & $\begin{array}{l}\text { Considers my schedule } \\
\text { before making appointments } \\
\text { or phone calls }\end{array}$ & -0.62 & 0.04 & 1.35 & 1.42 & 0.51 & Practice Structure \\
\hline $8^{a}$ & $\begin{array}{l}\text { Has a way to help find } \\
\text { information and resources }\end{array}$ & -0.51 & 0.04 & 0.65 & 0.42 & 0.75 & Future Promotion \\
\hline 3 & Decides together on goals & -0.44 & 0.05 & 0.88 & 0.81 & 0.69 & Decision Making \\
\hline 13 & $\begin{array}{l}\text { Works with me to adjust } \\
\text { our plan }\end{array}$ & -0.36 & 0.05 & 0.69 & 0.47 & 0.76 & Family Support \\
\hline 6 & $\begin{array}{l}\text { Works with me to plan when } \\
\text { there are big changes }\end{array}$ & -0.33 & 0.05 & 0.89 & 1.16 & 0.71 & Future Promotion \\
\hline 11 & Asks me what is working well & -0.24 & 0.04 & 0.70 & 0.87 & 0.74 & Strength-Based \\
\hline $23^{a}$ & $\begin{array}{l}\text { Talks with me about my child's } \\
\text { social and emotional wellbeing }\end{array}$ & -0.22 & 0.04 & 1.07 & 1.05 & 0.6 & Future Promotion \\
\hline 9 & $\begin{array}{l}\text { Offers ways to provide support } \\
\text { where my child usually spends } \\
\text { time }\end{array}$ & -0.15 & 0.05 & 0.85 & 0.67 & 0.73 & Practice Structure \\
\hline 5 & $\begin{array}{l}\text { Talks with me about how } \\
\text { decisions will affect my family }\end{array}$ & -0.07 & 0.05 & 0.88 & 0.76 & 0.72 & Decision Making \\
\hline 15 & $\begin{array}{l}\text { Asks about issues that affect } \\
\text { the well-being of my family }\end{array}$ & -0.04 & 0.05 & 1.02 & 0.77 & 0.69 & Family Support \\
\hline 14 & $\begin{array}{l}\text { Asks me about health or } \\
\text { emotional stresses I have }\end{array}$ & 0.10 & 0.06 & 1.02 & 0.82 & 0.69 & Family Support \\
\hline $24^{a}$ & $\begin{array}{l}\text { Helps me plan when changes } \\
\text { in my child's routine are needed }\end{array}$ & 0.14 & 0.04 & 0.85 & 0.87 & 0.71 & Family Support \\
\hline 19 & $\begin{array}{l}\text { Has a way to help me make } \\
\text { contact with community } \\
\text { resources }\end{array}$ & 0.23 & 0.06 & 0.93 & 0.81 & 0.73 & Care Coordination \\
\hline $22^{\mathrm{a}}$ & $\begin{array}{l}\text { Asks me about where I turn } \\
\text { to for support }\end{array}$ & 0.54 & 0.05 & 0.97 & 0.95 & 0.68 & Family Support \\
\hline 17 & $\begin{array}{l}\text { Asks about my family's beliefs } \\
\text { and practices }\end{array}$ & 0.70 & 0.07 & 1.11 & 1.20 & 0.66 & Cultural Competence \\
\hline 21 & $\begin{array}{l}\text { Gives me information to help } \\
\text { other people understand }\end{array}$ & 0.85 & 0.07 & 1.10 & 1.01 & 0.67 & Family Support \\
\hline 18 & $\begin{array}{l}\text { Asks if we want to integrate } \\
\text { alternative practices into plans }\end{array}$ & 0.89 & 0.07 & 1.05 & 0.97 & 0.66 & Cultural Competence \\
\hline 16 & $\begin{array}{l}\text { Asks if I would like other } \\
\text { community members to help } \\
\text { make decisions }\end{array}$ & 1.05 & 0.07 & 1.16 & 1.16 & 0.63 & Cultural Competence \\
\hline 20 & $\begin{array}{l}\text { Has a way to connect me } \\
\text { with other families }\end{array}$ & 1.10 & 0.08 & 1.36 & 1.32 & 0.59 & Family Support \\
\hline
\end{tabular}


Table 3 Difference in Family-Centered Care Outcomes Across the Two Intervention Arms of Connect for Health

\begin{tabular}{|c|c|c|c|}
\hline & Mean (SD) & $\beta$ Value $(95 \% \mathrm{Cl})$ & \\
\hline Study Arm & 1-y Follow-up & Difference & $p$-value \\
\hline \multicolumn{4}{|l|}{ FCCA mean score } \\
\hline $\begin{array}{l}\text { Enhanced primary care } \\
\text { plus health coach }\end{array}$ & $4.4(0.87)$ & $0.61(0.49,0.73)$ & $<.0001$ \\
\hline Enhanced primary care & $3.8(0.87)$ & 0.0 [Reference] & \\
\hline
\end{tabular}

Possible range of FCCA mean score: 1 (almost never) to 5 (almost always)

Most childhood obesity interventions are not familycentered [29] and that may help to explain the high attrition rates of weight management programs [30] and poor outcomes. For programs to help with lifestyle modifications [31] and behavioral changes, providers must be able to target, for example, goal setting, monitoring, and problem-solving while applying the principles of familycentered care [32]. In a review of childhood obesity interventions, Gallo and colleagues [33] found that the more family-centered an intervention was, the better the health outcomes of the children. This finding reinforces the importance of family-centered care in weight management programs. In the Connect for Health trial, as previously reported [11], children in both intervention arms showed improvements in their BMI z-scores. The higher perception of family-centered care in the enhanced primary plus health coaching arm may, though, help to explain the improved child health-related quality of life and it is possible that these children may show long-term improvements that persist after the intervention ends. While weight and physical health are primary objectives of pediatric weight management, outcomes such as quality of life and overall wellbeing are important as well [34].
Our study had several limitations. Family-centered care was a secondary outcome of this trial and was assessed after the intervention was completed, therefore we cannot draw conclusions about family-centeredness pre/post intervention. We calculated the mean of the responses on the mFCCA, whereas the original scale used a total score, therefore we were not able to use the cutoff scores that were applied in the original scale. The original scale calculated a neutral score and a score that indicated a high perception of family-centeredness. A cut-off score would be beneficial for assessing the quality of weight management programs. In addition, the scale contained 24 items that can be time consuming to administer which increases the likelihood of parents not completing the scale or skipping individual items. For this study our response rate was high, but if providers were administering this in busy waiting rooms the length of the scale may affect compliance. Because the scale loaded onto one factor, it provides opportunities in the future to develop a shortened scale that retains the psychometrics and the family-centered care principles.

\section{Conclusion}

In conclusion, the mFCCA for childhood obesity was found to be a reliable and valid instrument for assessing the family-centeredness of pediatric weight management programs. The mFCCA retained key principles for family-centered care and to our knowledge is the only existing scale to assess family centeredness of childhood obesity programs. By developing this tool to measure the family-centeredness of childhood obesity services, we are now able to evaluate the family-centeredness of programs and ensure optimal care is being delivered to

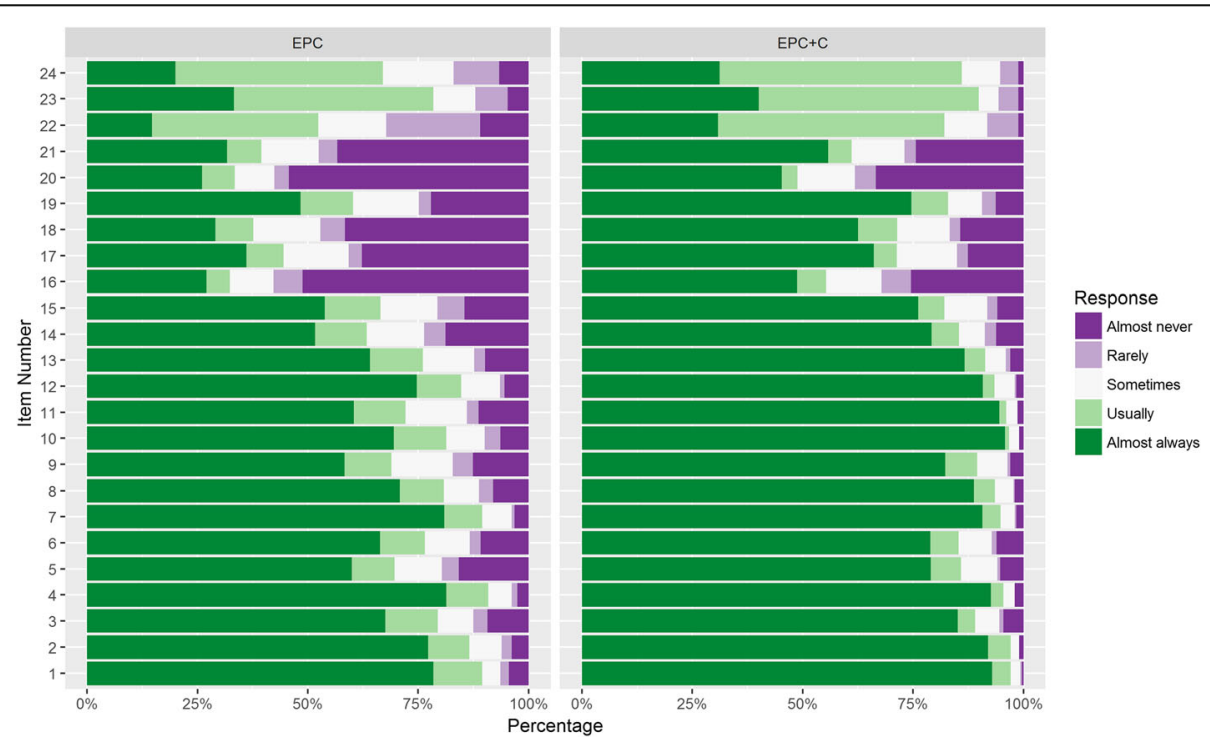

Fig. 2 The mean responses for the final items in the modified Family-Centered Care Assessment Tool for both intervention arms. EPC = Enhanced primary care. $\mathrm{EPC}+\mathrm{C}=$ Enhanced primary care plus health coaching 
children and their families. Our findings also suggest that pediatric weight management programs that include contextually-tailored, individual health coaching are perceived to be more family-centered in comparison to enhanced primary care alone. Pediatric weight management programs should assess the extent to which their services are family-centered and consider incorporating the mFCCA measure in their evaluation. Future studies should also examine the extent to which greater familycenteredness is associated with long term adherence, attrition, and weight status outcomes.

\section{Abbreviations}

FCCA: Family Centered Care Assessment tool; mFCCA: Modified version of the Family Centered-Care Assessment tool;; BMI: Body mass index; DIF: Differential Item Functioning

\section{Acknowledgements}

Not applicable.

\section{Authors' contributions}

MS (first author) drafted the manuscript, conceptualized and designed the study, analyzed and interpreted the data, and drafted the initial manuscript MS conceptualized and designed the study and critically reviewed the manuscript for important intellectual content. MG analyzed and interpreted the data, and critically reviewed the manuscript for important intellectual content. RM, EA, LF, CH, EJO, and JS assisted with interpretation of the data and critically reviewed the manuscript for important intellectual content. ET conceptualized and designed the study, interpreted the data, and critically reviewed the manuscript for important intellectual content. All authors read and approved the final manuscript.

\section{Funding}

This work was supported through award IH-1304-6739 from the Patient Centered Outcomes Research Institute. Dr. Sharifi was supported by grants K08 HS024332 and K12HS022986 from the Agency for Healthcare Research and Quality (AHRQ). Dr. Fiechtner's was supported by grant number K12HS022986 from the Agency for Healthcare Research and Quality and a 1K23HD090222-01A1 from the Eunice Kennedy Shriver National Institute of Child Health and Human Development. Dr. Taveras' time was supported by grant number K24DK105989 from the National Institutes of Health.

\section{Availability of data and materials}

The datasets used during the current study are available from the corresponding author on reasonable request.

\section{Ethics approval and consent to participate}

A fact sheet was provided to parents and verbal consent was obtained from those who agreed to complete a survey. The study protocol was approved by the Partners Health Care institutional review board.

\section{Consent for publication}

Not applicable.

\section{Competing interests}

The authors declare that they have no competing interests.

\section{Author details}

'Division of General Academic Pediatrics, Department of Pediatrics, MassGeneral Hospital for Children, 125 Nashua Street, Suite 860, Boston, MA 02114, USA. ${ }^{2}$ Department of Pediatrics, Harvard Medical School, Boston, MA USA. ${ }^{3}$ Section of General Pediatrics, Department of Pediatrics, Yale University School of Medicine, New Haven, CT, USA. ${ }^{4}$ Department of Pediatrics, Harvard Vanguard Medical Associates, Boston, MA, USA. ${ }^{5}$ Northeastern University, Boston, MA, USA. ${ }^{6}$ Division of Pediatric Gastroenterology and Nutrition, MassGeneral Hospital for Children, Boston, MA 02114, USA. 'Department of Medicine, Brigham and Women's Hospital, Boston, MA, USA. ${ }^{8}$ Department of Pediatrics, Wake Forest School of Medicine, Winston-Salem, NC, USA.
${ }^{9}$ Department of Nutrition, Harvard T.H. Chan School of Public Health, Boston, MA, USA.

Received: 7 January 2020 Accepted: 2 June 2020

Published online: 11 June 2020

\section{References}

1. Kuhlthau KA, Bloom S, Van Cleave J, Knapp AA, Romm D, Klatka K, et al. Evidence for family-centered care for children with special health care needs: a systematic review. Acad Pediatr. 2011;11(2):136-43. https://doi.org/ 10.1016/j.acap.2010.12.014

2. McAllister JW, Sherrieb K, Cooley WC. Improvement in the family-centered medical home enhances outcomes for children and youth with special healthcare needs. J Ambul Care Manag. 2009;32(3):188-96.

3. Kuo DZ, Houtrow AJ, Arango P, Kuhlthau KA, Simmons JM, Neff JM. Familycentered care: current applications and future directions in pediatric health care. Matern Child Health J. 2012;16(2):297-305.

4. King S, Teplicky R, King G, Rosenbaum P. Family-centered service for children with cerebral palsy and their families: a review of the literature. Semin Pediatr Neurol. 2004;11(1):78-86.

5. An M, Palisano RJ, Yi CH, Chiarello LA, Dunst CJ, Gracely EJ. Effects of a collaborative intervention process on parent empowerment and child performance: a randomized controlled trial. Phys Occup Ther Pediatr. 2017; 2638:1-15. https://doi.org/10.1080/01942638.2017.1365324.

6. Dunst CJ. Family centered practices: birth through high school. J Spec Educ 2002;36(3):141-9.

7. Skelton JA, Ennet IMB, Geiger AM. A systematic review of satisfaction and pediatric obesity treatment: new avenues for addressing attrition. J Healthc Qual. 2014;36(4):5-22.

8. Scholle SH, Vuong O, Ding L, Fry S, Gallagher P, Brown JA, et al. Development of and field-test results for the CAHPS PCMH survey. Med Care. 2012;50:S2-10

9. Wells N, Bronheim S, Zyzanski S, Hoover C. Psychometric evaluation of a consumer-developed family-centered care assessment tool. Matern Child Health J. 2015:19(9):1899-909.

10. Taveras EM, Marshall R, Sharifi M, Avalon E, Fiechtner L, Horan C, et al. Connect for health: design of a clinical-community childhood obesity intervention testing best practices of positive outliers. Contemp Clin Trials. 2015;45:287-95.

11. Taveras EM, Marshall R, Sharifi M, Avalon E, Fiechtner L, Horan C, et al. Comparative effectiveness of clinical-community childhood obesity interventions. JAMA Pediatr. 2017;171(8) Available from: http://archpedi. jamanetwork.com/article.aspx?doi=10.1001/jamapediatrics.2017.1325. Accessed 2 Feb 2018.

12. Tennant A, Conaghan PG. The Rasch measurement model in rheumatology: what is it and why use it? When should it be applied, and what should one look for in a Rasch paper? Arthritis Care Res. 2007;57(8):1358-62.

13. Boone WJ. Rasch analysis for instrument development: why, when, and how? CBE-Life Sci Educ. 2016;15(4):1-7.

14. Rasch G. Probalistic models for some intelligence and attainment tests. Chicago: University of Chicago Press; 1980.

15. Wright BD. Solving measurement problems with the Rasch model. J Educ Meas. 1977:14(2):97-116.

16. Mair $\mathrm{P}$, Hatzinger R. Extended Rasch modeling: The eRm package for the application of IRT models in R. J Stat Softw. 2007:20(9) Available from: http://www.jstatsoft.org/v20/i09/.

17. Muraki E. A generalized partial credit model: Applciation of an EM algorithm. Princeton; 1992

18. Masters GN. A rasch model for partial credit scoring. Psychometrika. 1982: 47(2):149-74.

19. Linacre JM. What do Infit and outfit, mean-square and standardized mean? Rasch Meas Trans. 2002;16(2):878.

20. Cureton EE. Corrected item-test correlations. Psychometrika. 1966;31(1):93-6.

21. Dorans NJ, Holland PW. DIF detection and description: mantel-Haenszel and standardization. Princeton; 1991.

22. Choi SW, Gibbons LE, Crane PK. Lordif: An R package for detecting differential item functioning using iterative hybrid ordinal logistic regression/item response theory and Monte Carlo simulations. J Stat Softw. 2011;39(8):1-30

23. Downey RG, King CV. Missing data in Likert ratings: a comparison of replacement methods. J Gen Psychol. 1998;125(2):175-91. 
24. Wright B, Stone M. Best test design. In: Measurement Essentials. Wilmington: Wide Range; 1999. p. 151-5.

25. Linacre JM. A user's guide to WINSTEPS and MINISTEP- Rasch-model computer programs: Program Manual 3.68.0. Chicago; 2009.

26. R Core Team. R: A language and environment for statistical computing. Vienna: R Foundation for Statistical Computing; 2013.

27. Rossen $L M$, Schoendorf KC. Measuring health disparities: trends in racialethnic and socioeconomic disparities in obesity among 2- to 18-year old youth in the United States, 2001-2010. Ann Epidemiol. 2012;22(10):698-704.

28. Price S, Ferisin S, Sharifi M, Steinberg D, Bennett G, Woli K, et al. Development and implementation of an interactive text messaging campaign to support behavior change in a childhood obesity randomized controlled trial. J Health Commun. 2015;20(7):843-50.

29. Davison KK, Lawson HA, Coatsworth JD. The family-centered action model of intervention layout and implementation (FAMILI): the example of childhood obesity. Health Promot Pract. 2012;13(4):454-61.

30. Skelton JA, Beech BM. Attrition in paediatric weight management: a review of the literature and new directions. Obes Rev. 2011;12:273-81.

31. Tyler DO, Horner SD. Family-centered collaborative negotiation: a model for facilitating behavior change in primary care. J Am Acad Nurse Pract. 2008; 20(4):194-203.

32. Pratt KJ, Skelton JA. Family functioning and childhood obesity treatment : a family systems theory-informed approach. Acad Pediatr. 2018; 18(6):620-7.

33. Gallo KP, Hill LC, Hoagwood KE, Olin SCS. A narrative synthesis of the components of and evidence for patient- and family-centered care. Clin Pediatr (Phila). 2016:55(4):333-46.

34. Armstrong SC, Skinner C. Defining "success " in childhood obesity interventions in primary care. Pediatrics. 2016;138(4):10-3.

\section{Publisher's Note}

Springer Nature remains neutral with regard to jurisdictional claims in published maps and institutional affiliations.

Ready to submit your research? Choose BMC and benefit from:

- fast, convenient online submission

- thorough peer review by experienced researchers in your field

- rapid publication on acceptance

- support for research data, including large and complex data types

- gold Open Access which fosters wider collaboration and increased citations

- maximum visibility for your research: over $100 \mathrm{M}$ website views per year

At $\mathrm{BMC}$, research is always in progress.

Learn more biomedcentral.com/submissions 